\title{
Adjusting COVID-19 Reports for Countries' Age Disparities: A Comparative Framework for Reporting Performances
}

Enes Eryarsoy a , Dursun Delen ${ }^{\mathrm{b}}$, Behrooz Davazdahemamic,

${ }^{a}$ School of Management, Sabanci University

Istanbul, Turkey. [enes.eryarsoy@sabanciuniv.edu.tr]

${ }^{\mathrm{b}}$ Center for Health Systems Innovation, Department of Management Science, Oklahoma State University, Stillwater, OK, USA. [dursun.delen@okstate.edu]

${ }^{c}$ Department of IT and Supply Chain Management, University of Wisconsin-Whitewater Whitewater, WI, USA [davazdab@uww.edu] 


\section{Abstract}

Objectives: The COVID-19 outbreak has impacted distinct health care systems differently. While the rate of disease for COVID-19 is highly age-variant, there is no unified and age/gender-inclusive reporting taking place. This renders the comparison of individual countries based on their corresponding metrics, such as CFR difficult. In this paper, we examine cross-country differences, in terms of the age distribution of symptomatic cases, hospitalizations, intensive care unit (ICU) cases, and fatalities. In addition, we propose a new quality measure (called dissonance ratio) to facilitate comparison of countries' performance in testing and reporting COVID-19 cases (i.e., their reporting quality).

Methods: By combining population pyramids with estimated COVID-19 agedependent conditional probabilities, we bridge country-level incidence data gathered from different countries and attribute the variability in data to country demographics.

Results: We show that age-adjustment can account for as much as a 22-fold difference in the expected number of fatalities across different countries. We provide case, hospitalization, ICU, and fatality breakdown estimates for a comprehensive list of countries. Also, a comparison is conducted between countries in terms of their performance in reporting COVID-19 cases and fatalities.

Conclusions: Our research sheds light on the importance of and propose a methodology to use countries' population pyramids for obtaining accurate estimates of the healthcare system requirements based on the experience of other, already affected, countries at the time of pandemics. 
Keywords: COVID-19; population pyramids; infectious disease; conditional probability; reporting performance; pandemic.

\section{Introduction}

The first COVID-19 outbreak took place in the city of Wuhan in the Hubei province of China. Despite strict and robust prevention measures taken in the city, the virus has spread the rest of the world in a matter of a few weeks. Within three months, the World Health Organization (WHO) declared the outbreak a pandemic. While some more significantly than others, the virus has taken its toll on all countries with no exception. The global impact of COVID-19 has been very profound and probably unprecedented since the Spanish flu (H1N1 influenza circa 1918). Due to the novelty of the virus, and the nonexistence of vaccination, health professionals have been trying to cope with the pandemic using symptomatic treatment regimes.

Many governments are seeking out forming different strategies that involve mitigating the spread until a method of prevention or a well-defined, and a successful treatment regime is found (1). The main focus of such mitigation effects is to alleviate the burden on healthcare systems by spreading out the diffusion of cases over a more extended period of time. While trying to achieve this, governments also face many uncertainties. One such uncertainty involves the absence of proven methods to accurately estimate the potential demand for healthcare services $(2,3)$.

At the time of this paper's writing, several governments, such as Italy and Spain, already had over $100 \%$ health services capacity utilization, while others were about to experience a similar influx of critical patients. It is clear that governments are in need of better understanding the dynamics of the spread for optimal or near-optimal resource allocation decisions. Unfortunately, 
due to the emergency and the gravity of the pandemic, and the lack of scantily found hard evidence causes, such decisions have been made through the seat-of-the-pants approaches.

Perhaps one of the reasons behind the lack of evidence is that there is no obvious way to map reports and studies pertaining to one country into another. Many regional differences make this mapping and transfer of the learnings and knowledge over to another domain particularly difficult. For the case of COVID-19, gender and age of the patient populations seem to be among the key drivers of such differences. Academics are acting swiftly to enrich the medical literature by reporting their findings on the virus-related population characteristics, diffusion patterns, treatment regimes, case dynamics, hospitalizations, ICU usages, and fatalities(4-7).

In this paper, as the first objective, we build on the studies and reports that involve age-based clinical fatality risks (CFR), infection fatality risks (IFR), hospitalizations, ICU usages, and fatal outcomes. Using the latest literature as well as expert opinions, we attempt to combine data from different regions in order to estimate and highlight: (i) country-level differences, and (ii) healthcare system demands for individual age groups. Specifically, using the data from six different countries, we study the spread of the virus for different age groups.

It is obvious that different countries, either due to their different policies or because of different healthcare infrastructures, do not perform equally well in conducting diagnostic tests and reporting a number of cases. Due to this fact, even countries with similar demographics and social distancing policies may report highly inconsistent numbers. Such inconsistencies will then make studying the disease's epidemiological characteristics challenging.

As the second objective, this paper seeks to propose an approach to compare the reporting performance of countries during the COVID-19 pandemic. For this purpose, we rely on the 
countries' similarities in terms of their age pyramids as well as the stage of the disease and assume that similar countries should experience similar population- and age-standardized numbers for their infections and death tolls. Considering US as the baseline, we then calculate a dissonance ratio for each country as a standardized measure of their performance in reporting cases and mortalities (i.e., a measure of the quality of their reports).

The rest of this paper is organized as follows: in the next section, a review of relevant studies from literature is provided. Following that, we describe our method and elaborate on the data used. The final section is dedicated to the findings and related discussions.

\section{Background}

The rapid spread of the novel coronavirus has even made the calculation of the rate of spread difficult. One frequently used way of measuring the spread is by computing the average number of secondary cases, or infections, that each case generates. This is known as the R-naught $\left(R_{0}\right)$ (a.k.a., reproduction number) of the virus. The $R_{0}$ 's time- and place-dependent nature (typically smaller in the South Asian countries, depending on social distancing interventions such as case isolation, partial or complete lockdowns, school closure, and distance working by the local authorities) is making modeling the spread of the virus a moving target (8).

Even though the literature on COVID-19 is rapidly expanding, there is still a lack of consensus among academics and other scientists on the dynamics of the spread. Different estimates, for instance, are reported for the disease's $R_{0}$ ranging from 1.94 through $6.7(6,9,10)$. This can perhaps be attributed to many reasons, such as the unpreparedness to a pandemic at this level, the lack of unified reporting systems due to diversity of health systems across the world, and the novelty of the pandemic itself. 
Studies also report varying figures for other epidemiological measures such as CFR or IFR. Several underlying reasons may explain these variabilities. Perhaps one of the most plausible reasons is the abundance of undocumented cases. In their study, Li et al. (10) highlight that one of the reasons for the rapid spread of the virus is lack of documentation. They estimate that around $86 \%$ of all infections were undocumented. Another study from South Korea suggests similar undocumented case percentages at around 55-86\% (11). News also suggests that even mortality cases often go unreported. A recent article in The Economist (12) highlighted stark differences between the number of expected death cases (including those attributed to COVID19) and the actual death cases. Their estimation, based on regions' normal death rates, suggests the actual death-toll of the novel COVID-19 being more than double of what is being reported in different regions in Italy, Spain, and France. Perhaps this may be one of the reasons for conflicting CFR and IFR figures reported in the literature. While some studies suggested an estimated case fatality risk of as high as 7.2\% (13) in Italy, other studies reported a CFR of 3.4\% in China (14), and 2.3\% using the age-adjusted Diamond Princess cruise ship data (15). More recent works report somewhat lower case fatality rates circa $1.4-1.5 \% \%(16,17)$, both using data from Wuhan.

Similar variations also hold for IFR. Studies report IFRs as low as $0.5 \%$ using the Diamond Princess cruise ship data (15), 0.94\%, and 0.657\% using Wuhan data (18) and (19), respectively. Even though these numbers significantly differ from each other, there seems to be (i) convergence to a CFR of $1.5 \%$ over time, (ii) CFR/IFR ratio appears to hover around 2-3, indicating as much as $40-70 \%$ asymptomatic cases of the virus.

One of the apparent reasons behind the differences in reported CFRs and IFRs is the different demographics in different countries. As the virus affects the elderly more than the young, the 
virus takes a different toll on each country, depending on its age demographics $(15,20)$. There may be several other reasons, including the fact that the age distribution of the infected population may differ from the overall age distribution. Hence, $R_{0}$ may significantly differ across age groups. However, there is a lack of by-age (and gender)-group reporting. For instance, Raj Bhopal (21), in his article expresses the importance and urgency of adjusting/reporting age and gender breakdowns of COVID-19 related data.

In this paper we pursue two objectives; First, we take into account the cross-country age disparities to handle such inconsistencies by providing country-independent conditional probabilities for each age group and then estimating the number of infections, hospitalizations, ICU visits, and mortality for each country given its age distribution. To this end, we assume that deaths, hospitalizations, and ICU usages are proxy measures for COVID-19 spread, also that similar spread patterns apply to each age group across countries - the virus is identical across all countries. We also demonstrate some evidence for the acceptability of these assumptions.

Second, relying on our findings from the first part, we propose a measure to assess the quality of testing and reporting COVID-19 cases across countries and comparing countries' performance in those manners. We believe that lack of such a measure in the literature has led to many studies relying on poor quality COVID-19 data in their analyses, which may lead to misleading conclusions.

\section{Method and Dataset}

Many of the existing studies that are focused on modeling the spread of the COVID-19 have been using a few different models such as susceptible-infected-recovered (SIR) and its covariates (mainly SEIR: susceptible-exposed-infected-recovered, or Sidarthe model) (22-26). These 
studies often ignore age-dependent variations from one country to another, or are limited to one country, or sometimes two (1).

In this study, instead of computing the spread of the virus, we look at the results of different scenarios. Specifically, we design three different spread scenarios (mild, moderate, and severe) by transferring knowledge learned from the seasonal flu pandemic as well as existing estimates for COVID-19 spread measures ( $\mathrm{R}_{0}$, proportion of symptomatic infections $(\mathrm{C})$, and proportion of reported cases) from the literature. Then taking into account expert opinions, we choose the best scenario (closest one to their opinions).

The best scenario is then used, along with the US (our baseline country) population age distribution, to calculate a set of conditional probabilities to estimate probability of infection, hospitalization, ICU admission, and death for a given person from each age group. At the end, the calculated probabilities are applied to the countries' age pyramids to estimate cases, hospitalizations, ICU usage, and fatalities in each country (adjusted for their population age distribution).

\section{Scenarios and Expert opinions}

While aggressive quarantines and enforcing/recommending social distancing can change the outcome of the burden on healthcare systems, the primary health care capacities are the bottleneck for almost all countries. The size of the susceptible population typically depends on different $R_{0}$ values. By enforcing/recommending social distancing, governments attempt to mitigate the situation and reduce this number (Figure 1). 


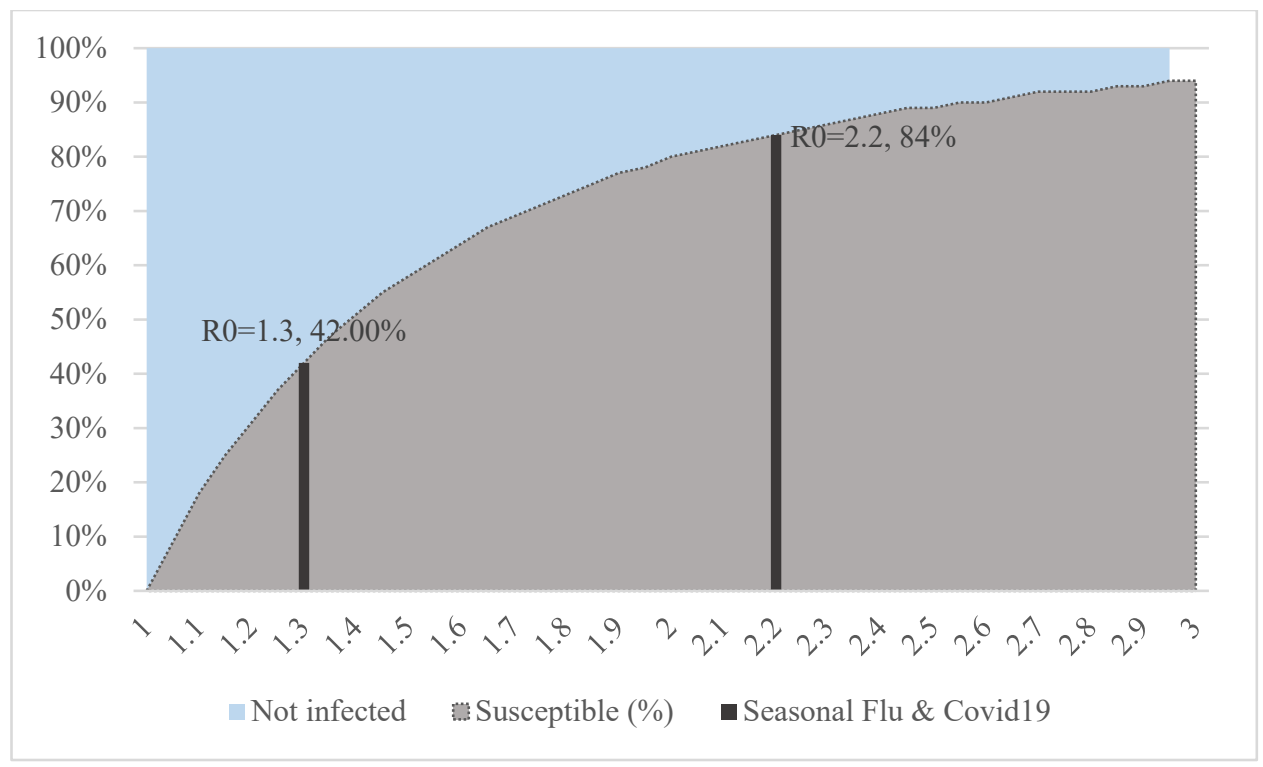

Figure 1. Different $R_{0}$ values and corresponding estimated percent of susceptible populations.

The novel coronavirus is often compared and contrasted against seasonal flu. Using CDC numbers over the last two flu seasons (2017-2019), we estimate the following table for the seasonal flu for comparison purposes.

Table 1. The seasonal flu numbers from the CDC.

\begin{tabular}{r|c|c|c}
\hline Seasonal flu (based on CDC data) & US Cases & $\begin{array}{c}\text { As \% of Susceptible } \\
\text { Population }\end{array}$ & Per 1M \\
\hline Susceptible population (R0=1.3) & $134.4 \mathrm{M}$ & $100.00 \%$ & 420,000 \\
Population with symptoms & $40 \mathrm{M}$ & $29.80 \%$ & $121 \mathrm{~K}$ \\
Medical Visits & $15 \mathrm{M}$ & $11.10 \%$ & $45.5 \mathrm{~K}$ \\
Hospitalization & $0.6 \mathrm{M}$ & $0.44 \%$ & 1,823 \\
Fatality & $40 \mathrm{~K}$ & $0.03 \%$ & 121 \\
\hline CFR & $0.03 \%$ &
\end{tabular}

We construct an analogous table to seasonal flu using expert opinions $(27,28)$ (See Table 2). To this end, we constructed different scenarios severe (Scenario 1) to mild (Scenario 3) based on the estimates provided by the existing literature. We construct this table for the United States. By making use of suggested estimates based on $(27,29)$, we create a range of possible $R_{0}$ values 
(i.e., 1.5-2.2) to estimate the percentage of susceptible population. Using the literature, we then estimate upper and lower limits for symptomatic cases, reported cases (not all of the symptomatic cases are reported), hospitalizations (as a percentage of reported cases), as well as ICU cases (in terms of cases), and fatalities in an age-adjusted manner.

Estimating fatalities is challenging since case fatality rates depend on a number of factors, including:

(i) The number of tests (and therefore, the number of positive cases) conducted each individual country. Many countries_-excluding countries such as Iceland, where a significant portion of the population was tested - conduct selective testing. This may involve a selection bias where only the people with severe enough symptoms may be tested.

(ii) The delay between the symptom onsets and the time of deaths.

(iii) The varying levels of adequacy/inadequacy of the healthcare systems.

(iv) The rates of smoking or the prevalence of chronical illnesses. We chose to use CFR of $1.5 \%$ for the United States for our analysis. 
medRxiv preprint doi: https://doi.org/10.1101/2020.08.31.20185223.this version posted September 2, 2020. The copyright holder for this preprint

(which was not certified by peer review) is the author/funder, who has granted medRxiv a license to display the preprint in perpetuity.

It is made available under a CC-BY-NC-ND 4.0 International license .

Table 2. Different COVID-19 spread estimates for the United States (numbers are in millions)

\begin{tabular}{l|c|c|c|c|c|}
\hline COVID-19 & Scen. 1 & Scen. 2 & Scen. 3 & $\begin{array}{c}\text { Expert } \\
\text { Opinion 1 }\end{array}$ & $\begin{array}{c}\text { Expert } \\
\text { Opinion 2 }\end{array}$ \\
\hline Susceptible population (overall $\left.\mathrm{R} 0=\left\{2.2^{1}, 1.8,1.5^{2}\right\}\right)$ & 276.4 & 240.2 & 190.8 & $160-210 \mathrm{M}$ & - \\
The population with symptoms $\left\{.50^{3}, .35, .20^{4}\right\}(\mathrm{C})$ & 138 & 84 & 38 & - & - \\
Reported cases (as the ratio of symptomatic cases) $\left\{.11^{5}, .15, .20^{6}\right\}$ & 27.6 & 13 & 4.2 & - & - \\
Hospitalizations $\left(36^{7,8}\right.$ of reported cases)(H) & 10 & 4.5 & 1.5 & $2.4-21 \mathrm{M}$ & - \\
\hline ICU patients $\left(\%\right.$ of Hospitalizations-7.4\% $\left.{ }^{9,10}\right)(\mathrm{I})$ & 0.7 & 0.34 & 0.11 & - & $\sim 0.08^{11}$ \\
Fatalities (D) & 0.41 & 0.19 & 0.063 & $0.2-1.7 \mathrm{M}$ & $0.03-0.12$ \\
\hline CFR $\left\{1.5^{12,13}\right\}$ & $1.50 \%$ & $1.50 \%$ & $1.50 \%$ & & \\
\hline
\end{tabular}

${ }^{1}$ (10)Error! Bookmark not defined. : estimates $R_{0}$ value as 2.2 for Wuhan data.

${ }^{2}$ (30) estimates $R_{0}$ value as 1.5 for South Korea where the virus is relatively better contained

${ }^{3}$ (17) finds a $50 \%$ chance of developing symptoms using Wuhan data.

${ }^{4}$ (31) suggests that the ratio of asymptomatic cases could be as high as $80 \%$.

${ }^{5}$ (32) uses South Korean data and similar age corrections and estimate that only around $11 \%$ of cases are reported in the US.

${ }^{6}$ (33) uses an estimation interval of $40-60 \%$ in their analysis. However, we construct our scenarios using similar to the US-based study.

${ }^{7}$ (34) CDC estimates also yield a similar number in the US. However, the data has no age breakdown and includes some unknown cases.

${ }^{8}$ The rate is estimated as 0.36 using conditional probabilities and age distributions based on Spanish Data (35)

${ }^{9}$ (29) estimates that around a fifth of hospitalization days will require ICU stays for the US. However, they do not provide projections based on the number of hospitalization and ICU cases. Their numbers are in seem consistent with Spanish data (35).

${ }^{10}$ The crude rate is estimated as 7.4\% of total hospitalizations using Spanish Data (35)Error! Bookmark not defined. . However, each case stays in ICU for an average of 15 days $(36) .(0.074 \times 15=1.11)$

${ }^{11}$ Assuming a 10-day average duration of stay.

${ }^{12}(16,17)$ indicated a CFR of $1.5 \%$.

${ }^{13}$ (37) indicates $0.7 \%$ CFR in Germany; such numbers usually come from countries where the spread is better contained.

Based on the characteristics of the COVID-19, the Center for Disease Control (CDC) estimated that 2.4 to 21 million Americans would require hospitalization, and a death-toll of as much as 480,000 may be expected (27). According to the same projection, the death toll could be any figure from 200,000 to as high as 1.7 million. Another more recent estimate assuming full social distancing through May (as of April 8, 2020), the White House estimated this figure to fall between 30,000 and 126,000 (28). These numbers are shown in the last two columns of Table 2. Given the closeness of estimates made by Scenario 3 (the mildest scenario) and the expert opinions, we rely on that scenario for establishing the conditional probabilities discussed in the following section. 


\section{Conditional Probabilities}

In this study, we use countries' age distributions (population pyramids) and data involving different countries to create country-independent conditional probabilities for each age group.

The severity of COVID-19 is also gender-dependent. However, due to the unavailability of data, we did not take gender into account.

As discussed earlier, we report our findings using the mildest of the three scenarios since its estimates turned out to be more consistent with the expert opinions (see Table 2). We use the following notation to formulate the conditional probabilities for each age group:

E: Events, $E=\{C$ : Case, A: Age, H: Hospitalization, I: Intensive Unit Care, D: Death) $P(C)$ : The probability of being infected with symptoms. Using the scenario-2 with $R_{0}=1.8$, we estimate the proportion of the susceptible population as 0.73 , with a $35 \%$ probability of developing symptoms: $P(C)=0.35 \times 0.73$

$P(R)$ : The probability of being a reported case: $P(R)=P(C) \times .15$ $P(H)$ : The probability of hospitalization. This number depends on the percentage of reported cases, as well as the size of the population with symptoms. Using 0.15 and $36 \%$ of the rate of hospitalization we use $(P(H)=P(C) \times .11 \times .36)$

$P(I)$ : The probability of needing $\operatorname{ICU}(P(I)=P(H) \times 0.074)$ $P(D)$ : The probability of death for the cases $(\mathrm{CFR})(P(D)=P(R) \times .015)$ $P\left(A_{i}\right)$ : The probability of each age group $i$ for a given country (using the country population pyramid)

$P\left(C \mid A_{i}\right)$ : The probability of being infected with symptoms given age group $i$

$$
P\left(C \mid A_{i}\right)=\frac{P\left(A_{i} \mid C\right)}{P\left(A_{i}\right)} P(C)
$$

where $P\left(A_{i} \mid C\right)$ : The probability of the age group $i$, given case.

We compute other conditional probabilities similarly for events $\{\mathrm{H}, \mathrm{I}, \mathrm{D}\}$ and then use them to simulate the mild scenario breakdowns for the United States. By using population pyramids and 
the US data, we replicate the same scenario for each individual country and report the results (per 1 million residents).

\section{Assessment of Quality of COVID-19 Case Reporting}

The second question this study seeks to address is that during the COVID-19 pandemic, how well different affected countries performed in conducting tests and reporting the cases. In order to answer this question, it is critical to have a base for comparing the countries' performance with one another (i.e., to assess their relative quality of reporting). For this purpose, through a series of calculations described below, we estimate an age-standardized expected number of cases and fatalities for each country, such that countries can be compared regardless of their age distributions. The procedure is explained below.

Using conditional probabilities, we calculate a set of successive measure for each country described below:

a. Age-Adjustment Fatality Coefficient (AAFC): We calculate the age-adjusted expected number of deaths by setting the global fatality baseline coefficient at "1" for the world. The coefficient value higher than " 1 " typically corresponds to an aging population. For instance, we estimate AAFC for Japan (one of the oldest nations in the world) as 3.41 (1037/204 from Table 1) and AAFC for Niger (the youngest nation) as 0.15. A 22-fold difference.

b. Age-Adjusted ICU Coefficient (AAICUC): The number of expected ICU cases corresponding to corresponding to AAFC of one. Calculated using the formula:

$$
\text { AAICUC }=\frac{\text { Expected ICU cases }}{\text { Expected Fatalities }} \times A A F C
$$

Countries with AAICUC of greater than the global average, 2.26, typically are expected to have heavier demand per capita for their intensive care units. 
c. Age-Adjusted Hospitalization Coefficient (AAHC): The number of expected hospitalization cases corresponding to AAFC of one. Calculated using the formula:

$$
\mathrm{AAHC}=\frac{\text { Expected Number of Hospitalizations }}{\text { Expected Fatalities }} \times A A F C
$$

d. Cumulative Fatalities (CF): Number of cumulative fatalities for each country as of May 13.

e. Day-Adjusted Cumulative Cases (DACC): Using a sliding lag window, we estimated the average number of days from the case reported to recovery (or fatality) as 8 days (38). Therefore, DACC corresponds to the reported cumulative number of cases 8 days prior to CF numbers.

f. Actual Case Fatality Risk (ACFR): Calculated as CF/DACC

g. Expected Infections per Fatality (EIPF): A recent study estimated the IFR of COVID-19 to be 1.3 for the US (39). Using this value for the US by adjusting AAFC of the US yields:

$$
E I P F_{U S}=\frac{1.89}{0.013}=145
$$

The figure represents the number of infections in the US, corresponding to one fatality at the baseline. Values for other countries are calculated using

$$
E I P F_{i}=\frac{R I P F_{i}}{R I P F_{U S}} \times E I P F_{U S}
$$

Countries with higher numbers are expected to report more cases than that of the US.

h. Reported Infections per Fatality (RIPF): Calculated as 1/ACFR for each country.

i. Age-adjusted Reported Fatalities per 1M (AARFPM): Some countries, given their population pyramids, are expected to report more cases. This column age and population (per 1M) adjusts the CF values for each country. Note that AARFPM values depend on the stage of the spread.

j. Dissonance Ratio (DR): Calculated as RIPF/ACFR. A value (typically less than 1) that indicates how well two or more countries with roughly the same AARFPM values 
performed in testing and reporting COVID-19 cases. Smaller DR values indicate possible under-reporting by the corresponding country.

\section{Results}

\section{Age-adjusted Estimates of COVID-19}

Unfortunately, the only source of data that explicitly provided the age breakdowns of hospitalization and ICU cases $(\mathrm{P}(\mathrm{A} \mid \mathrm{H})$, and $\mathrm{P}(\mathrm{A} \mid \mathrm{I}))$ we could found was Spain (35). After comparing the estimated $\mathrm{P}(\mathrm{H})$ and $\mathrm{P}(\mathrm{I})$ s from Spain data and the data from the Institute for Health Metrics and Evaluation (28), we concluded the numbers are consistent and decided to use age breakdowns from the Spanish dataset as the baseline for calculating conditional probabilities. A sample table, including some of the probabilities using the reports by the Spanish Ministry of Health, is given in Table 3.

Table 3. Probabilities and conditional probabilities for Spain

\begin{tabular}{c|ccccccccc}
\hline Age Group & $\mathrm{P}(\mathrm{A})$ & $\begin{array}{l}\text { \#Inf. } \\
\text { Cases }\end{array}$ & $\mathrm{P}(\mathrm{A} \mid \mathrm{C})$ & \#Hosp. & $\mathrm{P}(\mathrm{A} \mid \mathrm{H})$ & $\begin{array}{c}\text { \#ICU } \\
\text { cases }\end{array}$ & $\mathrm{P}(\mathrm{A} \mid \mathrm{I})$ & \#Deaths & $\mathrm{P}(\mathrm{A} \mid \mathrm{D})$ \\
\hline $\mathbf{0 - 9}$ & $9.3 \%$ & 130 & $0.6 \%$ & 35 & $0.45 \%$ & 1 & $0 \%$ & 0 & $0.0 \%$ \\
$\mathbf{1 0 - 1 9}$ & $10.0 \%$ & 226 & $1.1 \%$ & 20 & $0.26 \%$ & 1 & $0 \%$ & 1 & $0.1 \%$ \\
$\mathbf{2 0 - 2 9}$ & $10.0 \%$ & 1,352 & $6.6 \%$ & 200 & $2.6 \%$ & 10 & $2 \%$ & 4 & $0.5 \%$ \\
$\mathbf{3 0 - 3 9}$ & $13.2 \%$ & 2,386 & $11.7 \%$ & 431 & $5.6 \%$ & 18 & $3 \%$ & 3 & $0.4 \%$ \\
$\mathbf{4 0 - 4 9}$ & $17.0 \%$ & 3,190 & $15.6 \%$ & 778 & $10.1 \%$ & 45 & $8 \%$ & 9 & $1.1 \%$ \\
$\mathbf{5 0 - 5 9}$ & $14.9 \%$ & 3,433 & $16.8 \%$ & 1,074 & $13.9 \%$ & 106 & $18 \%$ & 20 & $2.5 \%$ \\
$\mathbf{6 0 - 6 9}$ & $11.1 \%$ & 3,179 & $15.6 \%$ & 1,432 & $18.6 \%$ & 162 & $28 \%$ & 63 & $7.8 \%$ \\
$\mathbf{7 0 - 7 9}$ & $8.4 \%$ & 3,304 & $16.1 \%$ & 1,858 & $24.1 \%$ & 192 & $34 \%$ & 164 & $20.4 \%$ \\
$\mathbf{8 0}+$ & $6.2 \%$ & 3,271 & $16.0 \%$ & 1,871 & $24.3 \%$ & 38 & $7 \%$ & 541 & $67.2 \%$ \\
\hline
\end{tabular}

Using age-corrections via conditional probabilities also shows that reported numbers are quite consistent across-countries (Table 4). As shown in this table, there is a 0.97 correlation between 
the estimated and the reported age group probabilities for the United States, suggesting the acceptable performance of the proposed approach for age adjustments.

Table 4- Computing age group probabilities for given cases in (i) Spain, (ii) in the US calculated using Spain data, and (iii) reported by CDC. While the correlation between (i) and (iii) is .88, the correlation between (i) and (ii) is as high as .97.

\begin{tabular}{c|rrrrr}
\hline Age Group & $P(A)_{U S}$ & $P(A)_{S p}$ & $P(A \mid C)_{S p}$ & $\begin{array}{c}P(A \mid C)_{U S} \text { from } \\
\text { Spain data }\end{array}$ & $\begin{array}{c}P(A \mid C)_{U S} \\
\text { reported }\end{array}$ \\
\hline $\mathbf{0 - 9}$ & $12.1 \%$ & $9.3 \%$ & $0.6 \%$ & $0.9 \%$ & $2.5 \%$ \\
$\mathbf{1 0 - 1 9}$ & $12.9 \%$ & $10.0 \%$ & $1.1 \%$ & $1.6 \%$ & $2.5 \%$ \\
$\mathbf{2 0 - 2 9}$ & $14.0 \%$ & $10.0 \%$ & $6.6 \%$ & $10.5 \%$ & $11.5 \%$ \\
$\mathbf{3 0 - 3 9}$ & $13.4 \%$ & $13.2 \%$ & $11.7 \%$ & $13.3 \%$ & $11.5 \%$ \\
$\mathbf{4 0 - 4 9}$ & $12.2 \%$ & $17.0 \%$ & $15.6 \%$ & $12.7 \%$ & $14.5 \%$ \\
$\mathbf{5 0 - 5 9}$ & $12.9 \%$ & $14.9 \%$ & $16.8 \%$ & $16.4 \%$ & $17.5 \%$ \\
$\mathbf{6 0 - 6 9}$ & $11.5 \%$ & $11.1 \%$ & $15.5 \%$ & $18.1 \%$ & $17.1 \%$ \\
$\mathbf{7 0 - 7 9}$ & $7.0 \%$ & $8.4 \%$ & $16.1 \%$ & $15.1 \%$ & $12.6 \%$ \\
$\mathbf{8 0 +}$ & $3.9 \%$ & $6.2 \%$ & $16.0 \%$ & $11.4 \%$ & $10.2 \%$ \\
\hline
\end{tabular}

We then use country demographics, CDC estimations for the US, and data sets available (shown in Table 5) to compute age-adjusted probabilities and number of cases for each of the events (Susceptible, Case with symptoms, Hospitalization, IUC case, and Deaths). For all countries, we report all numbers per 1 million for easy comparison in Appendix Table 1Appendix Table 2.

Table 5-Datasets used in this study

\begin{tabular}{l|ccccc}
\hline Country & South & & & & \\
Kurea(30) & Spain(35) & US(30) & China(19) & Italy(13) \\
Number of cases & 6,284 & 20,471 & 2,449 & 44,669 & $\sim 34,000$ \\
Number of hospitalizations & - & 7,699 & - & - & - \\
Number of ICU cases & - & 573 & - & - & - \\
\hline Number of fatalities in the study & 42 & 805 & 44 & 805 & 1,625 \\
\hline
\end{tabular}

Studies report different case- and death-related age-breakdowns for a variety of countries. We observed that taking conditional probabilities - based on population age distributions in 
individual countries - into account, we can help mitigate the variability in the reported results.

Figure 2 visually confirms the reduction in inconsistencies by taking age adjustments into account.
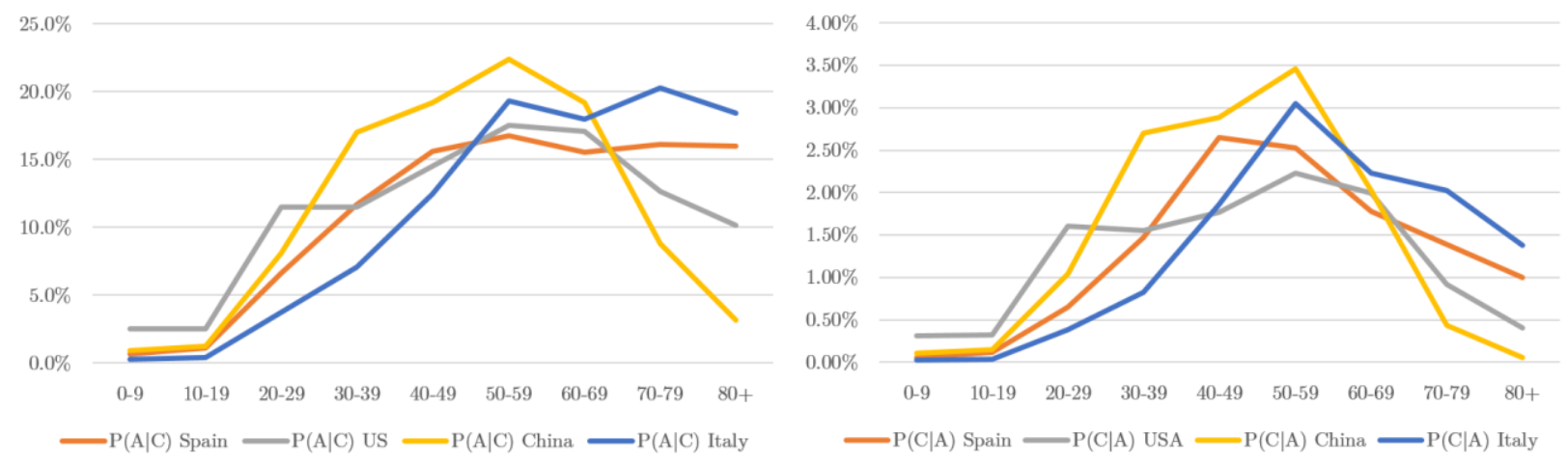

Figure 2. Age breakdown patterns of cases with (left) and without (right) taking country population pyramids (in terms of conditional probabilities) into account.

Figure 3 also highlights the age distribution differences for different events. ICU beds and invasive ventilators are in short supply, and some health systems prioritize younger patients over the older ones in order to increase the chances of survival. While debated from ethical viewpoints, the figure also demonstrates such preferences. 

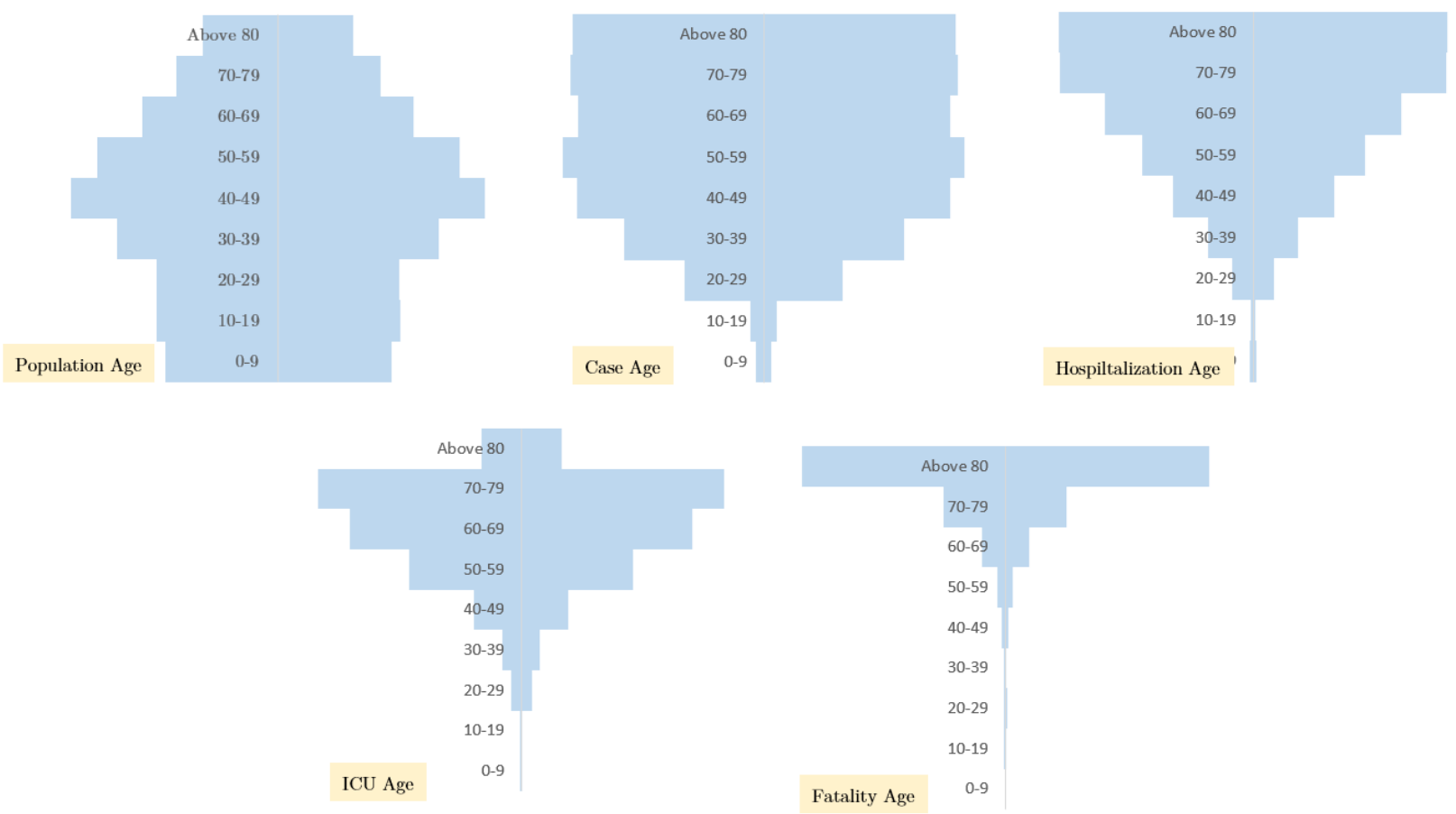

Figure 3. Age pyramids for cases, hospitalization, ICU uses, and fatalities for Spain.

\section{Assessing Countries' Reporting Quality}

As explained earlier, for each country, we calculated a dissonance ratio (DR) number indicating

how well the governments have done in conducting tests and reporting cases, given some age-

standardized expected number of cases. The DR estimates (along with other related measures)

are reported in detail in Appendix Table 2.

At the time of writing this manuscript, some of the countries were still experiencing the early stages of the breakout. At the end of the COVID-19 spread, the Appendix Table 2 would include similar values in column AARFPM across all countries. As AARFPM values indicate the progress for the breakout, we filtered out the countries with less than 10 AARFPM for better interpretability. This column, therefore, may be interpreted as a crude measure of reliability (hence progress of the spread) for dissonance ratios (i.e., the higher this value, the more evidence we have for the magnitude of the dissonance). Therefore, the table is ordered by AARFPM 
values rather than dissonance ratios. The correct way of interpreting the results is by comparing the DR values of row-wise nearby countries (with similar AARFPM values). For instance, Finland, Hungary, and Israel have similar AARFPM values (20.1, 20.2, and 20.6, respectively) indicating them being at the same stage of the epidemic. However, their Dissonance Ratios are $0.04,0.23$, and 0.55 , respectively. This indicates comparatively better case reporting (including testing) by Israel. At the end of the pandemic, all countries in the table are expected to have roughly the same AARFPM values, making reporting quality of them all comparable to one another through the proposed standardized DR measure.

\section{Discussion}

In this paper, we focus on age-dependent breakdowns of cases, hospitalizations, ICU usages, and fatalities (events) using a range of scenarios. We construct these scenarios by using expert views and existing reports in the literature and based on the US data. We then use conditional probabilities to compute age-standardized breakdowns for the events for all individual countries.

Our results propose a few important implications. First, the results highlight the effect of demographical differences across countries on COVID-19 spread. Figure 4 indicates a comparison between Niger and Japan (as the youngest and oldest populations in the world, respectively). It suggests, provided that everything else remains the same, the death toll difference due to age demographics could be as much as 20 times (47 vs. 1,037 deaths per 1M population according to Appendix Table 1).

Second, our results have the potential to help decision-makers to accommodate age-specific aspects of the spread. Creating different age-based isolation strategies, depending on the agedemographics of individual countries, may be considered. This is essentially important given the 
limited capacity of health care systems in the affected countries. At this time, one of the major concerns of the governments in the countries affected by COVID-19 is to have reliable estimates of medical requirements to plan ahead proper measures. We argue that providing such estimates based on age groups can give the authorities a clearer picture of what they should expect in different regions of their countries based on the demographic profile of the population in each region. The proposed approach is not exclusively for COVID-19 and may be employed by the decision-makers for estimating capacity requirements in the future epidemic situations.

Also, our study attempts to combine several parameters calculated or taken from different academic papers, reports, or data sources together in creating a range of scenarios. While this approach provides a somewhat holistic view of the phenomenon, it also omits other country-level differences such as social isolation policies, prevention strategies, and the effectiveness of the individual healthcare systems (i.e., our research limitations). Future research may extend the proposed approach by involving such factors (upon the availability of data for them) in the calculation of conditional probabilities. Appendix Table 1 must be interpreted as a comparison tool for different countries' exposure to the virus.

Additionally, we propose an approach to compare countries' performance in reporting COVID19 cases. Clearly, not all countries have the same healthcare infrastructure to conduct enough number of tests to identify infected people. Despite these differences, official reports published by the governments of different countries are being used in a similar manner to study the characteristics of the novel coronavirus, which may cause significant bias to their findings. It is crucial then to provide a means to recognize those countries that perform better in running tests and reporting cases, thereby providing more reliable numbers for studying the pandemic. Appendix Table 2 lays out a base for comparing the reporting performance of the countries by 
taking into account their age disparities as well as the progress stage of the disease. Using that tool, researchers could have a better understanding of the accuracy of reported numbers by each country by looking into their dissonance ratio number. 


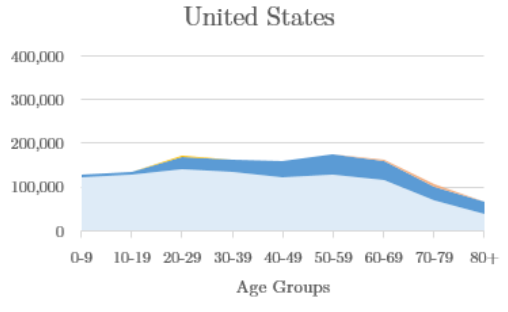

US - C Cases $=\mathrm{H}$ Cases $\| \mathrm{I}$ cases $-\mathrm{D}$ cases

Niger

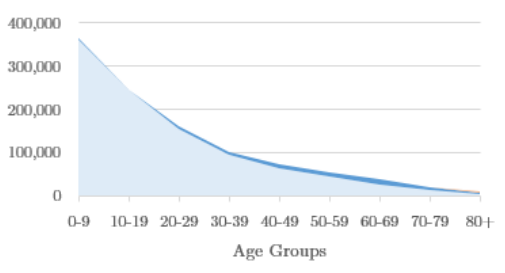

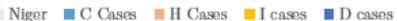

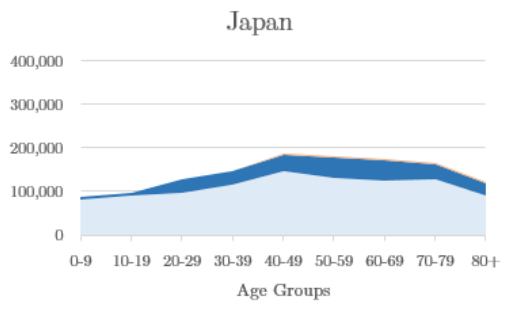

Japan - C Cases 4 H Coses I I cases -D cases
United States

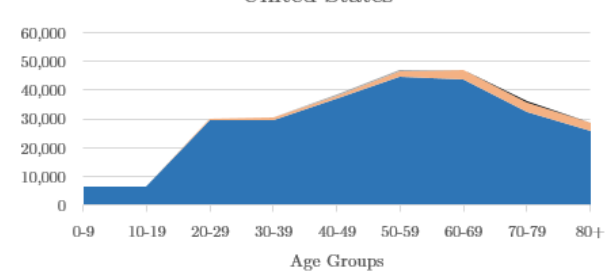

- C Cases $=\mathrm{H}$ Cases $\mathrm{EI}$ cases $\quad$ - D cases

Niger

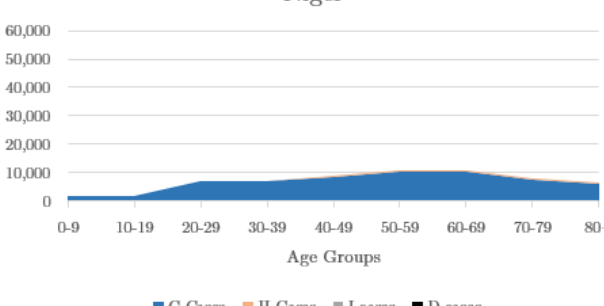

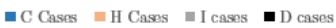

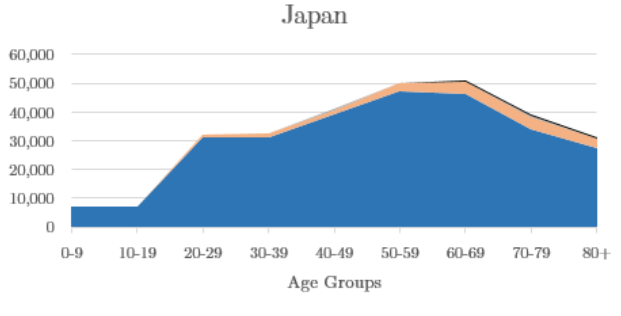

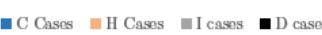

United States

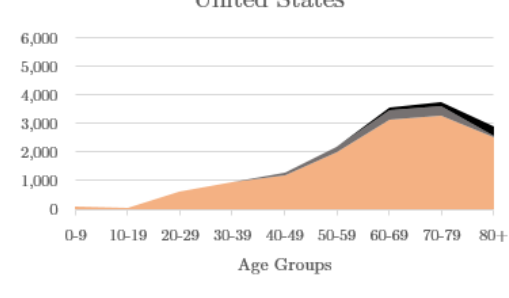

WH Casse $-\mathrm{I}$ casss - D cases

Niger

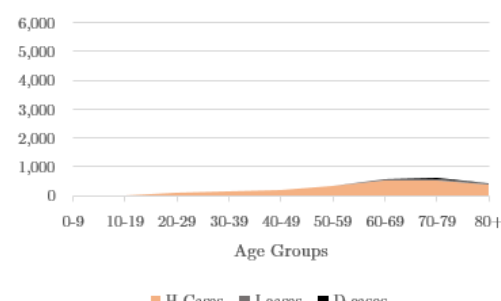

In H Cases - I cases - D cases

Japan

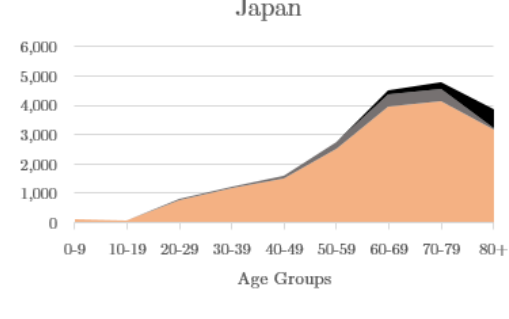

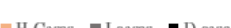

United States

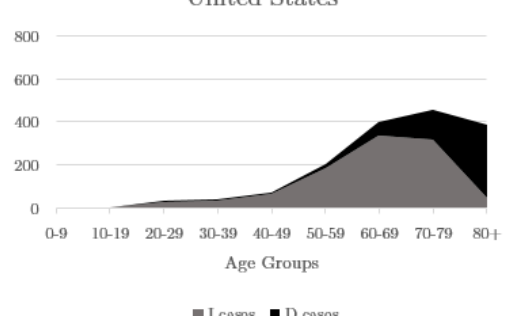

I cases - D cases

Niger

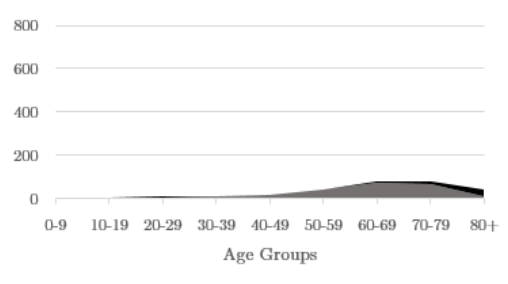

- I cases - D cases

Japan

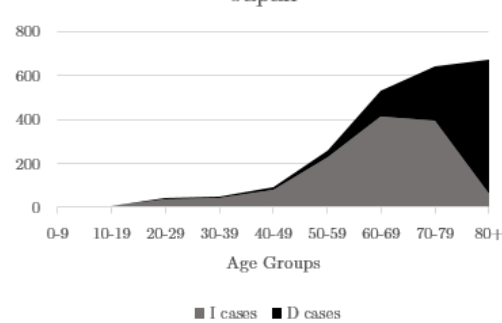

- I cases - D cases

Figure 4. Age-dependent event estimations for the US, the country with the youngest population in the world (Niger), and with the oldest (Japan). y-axis is for scaling purposes based on one of the scenarios per $1 \mathrm{M}$. 


\section{References}

1. Ferguson NM, Laydon D, Nedjati-Gilani G, Imai N, Ainslie K, Baguelin M, et al. Impact of non-pharmaceutical interventions (NPIs) to reduce COVID-19 mortality and healthcare demand. ImperialAcUk [Internet]. 2020 [cited 2020 May 27];(March):3-20. Available from: https://doi.org/10.25561/77482

2. Nap RE, Andriessen MPHM, Meessen NEL, Van Der Werf TS. Pandemic influenza and hospital resources. Emerg Infect Dis. 2007;13(11):1714-9.

3. Weissman GE, Crane-Droesch A, Chivers C, Luong T, Hanish A, Levy MZ, et al. Locally Informed Simulation to Predict Hospital Capacity Needs During the COVID-19 Pandemic. Ann Intern Med. 2020 Apr 7;

4. Jin J-M, Bai P, He W, Wu F, Liu X-F, Han D-M, et al. Gender Differences in Patients With COVID-19: Focus on Severity and Mortality. Front Public Heal [Internet]. 2020 Apr 29 [cited 2020 May 27];8:152. Available from:

https:/www.frontiersin.org/article/10.3389/fpubh.2020.00152/full

5. Wenham C, Smith J, Morgan R. COVID-19: the gendered impacts of the outbreak. Vol. 395, The Lancet. Lancet Publishing Group; 2020. p. 846-8.

6. $\mathrm{Wu} \mathrm{Z}, \mathrm{McGoogan} \mathrm{JM}$. Characteristics of and Important Lessons from the Coronavirus Disease 2019 (COVID-19) Outbreak in China: Summary of a Report of 72314 Cases from the Chinese Center for Disease Control and Prevention. Vol. 323, JAMA - Journal of the American Medical Association. American Medical Association; 2020. p. 1239-42.

7. Zhou F, Yu T, Du R, Fan G, Liu Y, Liu Z, et al. Clinical course and risk factors for mortality of adult inpatients with COVID-19 in Wuhan, China: a retrospective cohort study. Lancet. 2020 Mar 28;395(10229):1054-62.

8. De Brouwer E, Raimondi D, Moreau Y. Modeling the COVID-19 outbreaks and the effectiveness of the containment measures adopted across countries. medRxiv [Internet]. 2020 Apr 19 [cited 2020 May 27];2020.04.02.20046375. Available from: http://medrxiv.org/content/early/2020/04/19/2020.04.02.20046375.abstract

9. Fanelli D, Piazza F. Analysis and forecast of COVID-19 spreading in China, Italy and France. Chaos, Solitons and Fractals. 2020 May 1;134.

10. Li Q, Guan X, Wu P, Wang X, Zhou L, Tong Y, et al. Early transmission dynamics in Wuhan, China, of novel coronavirus-infected pneumonia. Vol. 382, New England Journal of Medicine. Massachussetts Medical Society; 2020. p. 1199-207.

11. Kim DH, Choe YJ, Jeong JY. Understanding and Interpretation of Case Fatality Rate of Coronavirus Disease 2019. J Korean Med Sci. 2020 Mar 1;35(12):e137.

12. Fatal flaws - Covid-19's death toll appears higher than official figures suggest [Internet]. The Economist. 2020 [cited 2020 May 27]. Available from: https:/www.economist.com/graphic-detail/2020/04/03/covid-19s-death-toll-appearshigher-than-official-figures-suggest 
13. Onder G, Rezza G, Brusaferro S. Case-Fatality Rate and Characteristics of Patients Dying in Relation to COVID-19 in Italy. Vol. 323, JAMA - Journal of the American Medical Association. American Medical Association; 2020. p. 1775-6.

14. Wilson N, Kvalsvig A, Barnard LT, Baker MG. Case-Fatality Risk Estimates for COVID19 Calculated by Using a Lag Time for Fatality. Emerg Infect Dis. 2020 Mar 13;26(6).

15. Russell TW, Hellewell J, Jarvis CI, Zandvoort K Van, Abbott S, Ratnayake R, et al. Estimating the infection and case fatality ratio for coronavirus disease (COVID-19) using age-adjusted data from the outbreak on the Diamond Princess cruise ship, February 2020. Vol. 25, Eurosurveillance. European Centre for Disease Prevention and Control (ECDC); 2020 .

16. Guan WJ, Ni ZY, Hu Y, Liang WH, Ou CQ, He JX, et al. Clinical Characteristics of Coronavirus Disease 2019 in China. N Engl J Med. 2020 Apr 30;382(18).

17. Wu JT, Leung K, Bushman M, Kishore N, Niehus R, de Salazar PM, et al. Estimating clinical severity of COVID-19 from the transmission dynamics in Wuhan, China. Nat Med. 2020 Apr 1;26(4):506-10.

18. Famulare M. 2019-nCoV: preliminary estimates of the confirmed-case-fatality-ratio and infection-fatality-ratio, and initial pandemic risk assessment [Internet]. [cited 2020 May 27]. Available from: https://institutefordiseasemodeling.github.io/nCoVpublic/analyses/first_adjusted_mortality_estimates_and_risk_assessment/2019-nCoVpreliminary_age_and_time_adjusted_mortality_rates_and_pandemic_risk_assessment.htm 1

19. Verity R, Okell LC, Dorigatti I, Winskill P, Whittaker C, Imai N, et al. Estimates of the severity of COVID-19 disease. medRxiv. 2020 Mar 13;2020.03.09.20033357.

20. Riou J, Hauser A, Counotte MJ, Althaus CL. ADJUSTED AGE-SPECIFIC CASE FATALITY RATIO DURING THE COVID-19 EPIDEMIC IN HUBEI, CHINA. [cited 2020 May 27]; Available from: https://doi.org/10.1101/2020.03.04.20031104

21. Bhopal R. Covid-19 worldwide: We need precise data by age group and sex urgently. Vol. 369, The BMJ. BMJ Publishing Group; 2020.

22. Fang Y, Nie Y, Penny M. Transmission dynamics of the COVID-19 outbreak and effectiveness of government interventions: A data-driven analysis. J Med Virol. 2020 Jun 1

23. Liu Y, Gayle AA, Wilder-Smith A, Rocklöv J. The reproductive number of COVID-19 is higher compared to SARS coronavirus. J Travel Med [Internet]. 2020 Feb 13;27(2). Available from: https://doi.org/10.1093/jtm/taaa021

24. Peng L, Yang W, Zhang D, Zhuge C, Hong L. Epidemic analysis of COVID-19 in China by dynamical modeling. medRxiv. 2020 Feb 18;2020.02.16.20023465.

25. Radulescu A, Cavanagh K. Management strategies in a SEIR model of COVID 19 community spread. 2020 Mar 24 [cited 2020 May 27]; Available from:

http://arxiv.org/abs/2003.11150 
26. Giordano G, Blanchini F, Bruno R, Colaneri P, Di Filippo A, Di Matteo A, et al. A SIDARTHE Model of COVID-19 Epidemic in Italy. Nat Med [Internet]. 2020 Mar 22 [cited 2020 May 27]; Available from: http://arxiv.org/abs/2003.09861

27. Fink S. Worst-Case Estimates for U.S. Coronavirus Deaths - The New York Times [Internet]. 2020 [cited 2020 May 27]. Available from: https://www.nytimes.com/2020/03/13/us/coronavirus-deaths-estimate.html

28. IHME. COVID-19 [Internet]. Institute for Health Metrics and Evaluation. 2020 [cited 2020 May 27]. Available from: https://covid19.healthdata.org/united-states-of-america

29. Murray CJ. Forecasting COVID-19 impact on hospital bed-days, ICU-days, ventilatordays and deaths by US state in the next 4 months. medRxiv. 2020 Mar 30;114:2020.03.27.20043752.

30. Shim E, Tariq A, Choi W, Lee Y, Chowell G. Transmission potential and severity of COVID-19 in South Korea. Int J Infect Dis. 2020 Apr 1;93:339-44.

31. Day M. Covid-19: four fifths of cases are asymptomatic, China figures indicate. BMJ. 2020 Apr 2;369:m1375.

32. Lachmann A, Jagodnik KM, Giorgi FM, Ray F. Correcting under-reported COVID-19 case numbers: estimating the true scale of the pandemic. medRxiv. 2020;

33. Magal P, Webb G. Predicting the number of reported and unreported cases for the COVID-19 epidemic in South Korea, Italy, France and Germany. medRxiv. 2020 Mar 24;2020.03.21.20040154.

34. Chow N, Fleming-Dutra K, Gierke R, Hall A, Hughes M, Pilishvili T, et al. Preliminary estimates of the prevalence of selected underlying health conditions among patients with coronavirus disease 2019 - United States, February 12-March 28, 2020. Vol. 69, Morbidity and Mortality Weekly Report. Department of Health and Human Services; 2020. p. 382-6.

35. Ministerio de Sanidad [Internet]. 2020 [cited 2020 May 27]. Available from: https://www.mscbs.gob.es/profesionales/cargarNotas.do

36. Analysis of COVID-19 data on numbers in intensive care from Italy: European Society of Anaesthesiology (ESA) - ESA HQ [Internet]. [cited 2020 May 27]. Available from: https://www.esahq.org/esa-news/analysis-of-covid-19-data-on-numbers-in-intensive-carefrom-italy-european-society-of-anaesthesiology-esa/

37. Omer SB, Malani P, Del Rio C. The COVID-19 Pandemic in the US: A Clinical Update. Vol. 323, JAMA - Journal of the American Medical Association. American Medical Association; 2020. p. 1767-8.

38. Delen D, Eryarsoy E, Davazdahemami B. No Place Like Home: Cross-National Data Analysis of the Efficacy of Social Distancing During the COVID-19 Pandemic. JMIR Public Heal Surveill [Internet]. 2020 May 28;6(2):e19862. Available from: http://publichealth.jmir.org/2020/2/e19862/

39. Basu A. Estimating The Infection Fatality Rate Among Symptomatic COVID-19 Cases In 
The United States. Health Aff (Millwood) [Internet]. 2020 May 7 [cited 2020 May 27];101377hlthaff202000455. Available from:

http://www.ncbi.nlm.nih.gov/pubmed/32379502

\section{Appendix}

Appendix Table 1-Scenario-2 based event breakdowns for individual countries

\begin{tabular}{|c|c|c|c|c|c|}
\hline Country & $\begin{array}{c}\text { Population } \\
\text { (K) }\end{array}$ & $\begin{array}{c}\text { Cases per } \\
1 \mathrm{M} \\
\end{array}$ & Hosp. per 1M & $\begin{array}{c}\text { ICU per } \\
1 \mathrm{M} \\
\end{array}$ & Deaths per $1 \mathrm{M}$ \\
\hline Portugal & 10,196 & 275,770 & 16,717 & 1,218 & 854 \\
\hline Germany & 83,783 & 275,671 & 16,521 & 1,194 & 852 \\
\hline Italy & 60,461 & 275,463 & 16,903 & 1,223 & 902 \\
\hline Greece & 10,423 & 273,517 & 16,472 & 1,173 & 879 \\
\hline Switzerland & 8,655 & 272,148 & 15,554 & 1,130 & 720 \\
\hline Bulgaria & 6,949 & 271,055 & 16,053 & 1,216 & 706 \\
\hline Japan & 126,475 & 271,042 & 17,430 & 1,256 & 1,037 \\
\hline Hungary & 9,660 & 270,439 & 15,464 & 1,160 & 665 \\
\hline Finland & 5,542 & 270,389 & 16,135 & 1,195 & 784 \\
\hline Netherlands & 17,136 & 269,922 & 15,626 & 1,169 & 705 \\
\hline Spain & 46,733 & 269,495 & 15,673 & 1,117 & 772 \\
\hline Republic of Korea & 51,270 & 269,133 & 14,500 & 1,102 & 556 \\
\hline Romania & 19,236 & 268,786 & 15,330 & 1,133 & 677 \\
\hline Poland & 37,847 & 267,820 & 15,109 & 1,113 & 656 \\
\hline Belgium & 11,589 & 267,496 & 15,314 & 1,104 & 736 \\
\hline Denmark & 5,792 & 266,784 & 15,340 & 1,144 & 694 \\
\hline Czech & 10,708 & 265,466 & 15,251 & 1,153 & 642 \\
\hline Sweden & 10,099 & 264,504 & 15,248 & 1,108 & 729 \\
\hline United Kingdom & 67,886 & 264,035 & 14,909 & 1,078 & 694 \\
\hline Ukraine & 43,734 & 263,634 & 14,445 & 1,065 & 598 \\
\hline Norway & 5,421 & 261,559 & 14,405 & 1,060 & 619 \\
\hline Cuba & 11,326 & 260,576 & 13,965 & 1,038 & 562 \\
\hline Belarus & 9,449 & 256,685 & 13,641 & 1,004 & 548 \\
\hline US & 329,064 & 255,500 & 13,797 & 1,021 & 575 \\
\hline New Zealand & 4,822 & 254,069 & 13,778 & 1,022 & 576 \\
\hline Australia & 25,498 & 253,440 & 13,696 & 993 & 590 \\
\hline
\end{tabular}




\begin{tabular}{|c|c|c|c|c|c|}
\hline Country & $\begin{array}{l}\text { Population } \\
\text { (K) }\end{array}$ & $\begin{array}{c}\text { Cases per } \\
1 \mathrm{M} \\
\end{array}$ & Hosp. per 1M & $\begin{array}{c}\text { ICU per } \\
1 \mathrm{M}\end{array}$ & Deaths per $1 \mathrm{M}$ \\
\hline Russian Federation & 145,935 & 253,217 & 13,567 & 997 & 551 \\
\hline Uruguay & 3,474 & 244,333 & 12,945 & 912 & 586 \\
\hline Ireland & 4,938 & 242,002 & 12,670 & 941 & 493 \\
\hline Chile & 19,116 & 234,534 & 11,579 & 853 & 429 \\
\hline China & $1,439,324$ & 227,809 & 10,805 & 875 & 326 \\
\hline Argentina & 45,197 & 213,004 & 10,468 & 759 & 400 \\
\hline Israel & 8,655 & 211,875 & 10,745 & 771 & 438 \\
\hline Sri Lanka & 21,413 & 211,258 & 10,060 & 822 & 304 \\
\hline Brazil & 212,560 & 207,735 & 9,592 & 722 & 318 \\
\hline Colombia & 50,883 & 198,163 & 9,060 & 679 & 301 \\
\hline World & $\underline{7,794,799}$ & $\underline{197,313}$ & $\underline{9,131}$ & $\underline{688}$ & $\underline{304}$ \\
\hline Tunisia & 11,819 & 196,661 & 8,884 & 680 & 281 \\
\hline Turkey & 84,339 & 195,387 & 8,928 & 677 & 290 \\
\hline Peru & 32,972 & 191,468 & 8,717 & 649 & 290 \\
\hline Viet Nam & 97,338 & 190,509 & 8,391 & 608 & 284 \\
\hline Kazakhstan & 18,776 & 181,352 & 8,042 & 604 & 258 \\
\hline $\begin{array}{l}\text { Venezuela (Bolivarian } \\
\text { Republic of) }\end{array}$ & 28,437 & 180,853 & 8,072 & 628 & 247 \\
\hline Mexico & 128,933 & 177,978 & 7,887 & 589 & 256 \\
\hline Dominica & 10,847 & 174,998 & 7,815 & 574 & 263 \\
\hline Azerbaijan & 10,139 & 173,391 & 7,261 & 557 & 214 \\
\hline Ecuador & 17,643 & 173,165 & 7,726 & 571 & 257 \\
\hline Morocco & 36,910 & 172,690 & 7,503 & 604 & 214 \\
\hline Malaysia & 32,365 & 168,392 & 7,211 & 575 & 205 \\
\hline Bolivia & 11,674 & 163,184 & 7,436 & 533 & 267 \\
\hline $\begin{array}{l}\text { Iran (Islamic Republic } \\
\text { of) }\end{array}$ & 83,993 & 161,603 & 6,787 & 541 & 189 \\
\hline Algeria & 43,852 & 159,997 & 6,934 & 521 & 217 \\
\hline Paraguay & 7,132 & 155,116 & 6,797 & 516 & 213 \\
\hline India & $1,380,004$ & 154,638 & 6,475 & 529 & 176 \\
\hline Indonesia & 273,523 & 154,124 & 6,343 & 531 & 165 \\
\hline Bangladesh & 164,690 & 142,614 & 5,915 & 448 & 177 \\
\hline Philippines & 109,581 & 136,985 & 5,625 & 457 & 152 \\
\hline Nepal & 29,138 & 133,698 & 5,539 & 465 & 145 \\
\hline South Africa & 59,308 & 132,704 & 5,360 & 455 & 135 \\
\hline
\end{tabular}




\begin{tabular}{|c|c|c|c|c|c|}
\hline Country & $\begin{array}{l}\text { Population } \\
\text { (K) }\end{array}$ & $\begin{array}{c}\text { Cases per } \\
1 \mathrm{M}\end{array}$ & Hosp. per 1M & $\begin{array}{c}\text { ICU per } \\
1 \mathrm{M}\end{array}$ & Deaths per $1 \mathrm{M}$ \\
\hline Turkmenistan & 6,031 & 129,106 & 5,120 & 398 & 143 \\
\hline Egypt & 102,335 & 129,065 & 5,306 & 440 & 140 \\
\hline Uzbekistan & 33,470 & 128,528 & 5,038 & 401 & 135 \\
\hline Syrian Arab Republic & 17,500 & 125,473 & 5,083 & 400 & 141 \\
\hline Pakistan & 220,892 & 112,174 & 4,521 & 370 & 119 \\
\hline Jordan & 10,205 & 108,890 & 4,301 & 345 & 114 \\
\hline Saudi Arabia & 34,815 & 102,129 & 3,777 & 317 & 91 \\
\hline Sudan & 43,849 & 93,224 & 3,681 & 308 & 93 \\
\hline Ethiopia & 114,964 & 88,752 & 3,545 & 291 & 93 \\
\hline Iraq & 40,223 & 88,523 & 3,410 & 280 & 87 \\
\hline Iraq & 40,223 & 88,523 & 3,410 & 280 & 87 \\
\hline South Sudan & 11,195 & 85,682 & 3,366 & 285 & 84 \\
\hline State of Palestine & 5,101 & 85,658 & 3,307 & 278 & 82 \\
\hline Madagascar & 27,692 & 82,226 & 3,138 & 265 & 77 \\
\hline Ghana & 31,073 & 79,587 & 2,934 & 280 & 63 \\
\hline Senegal & 16,745 & 77,735 & 2,989 & 261 & 71 \\
\hline $\begin{array}{l}\text { Democratic Republic of } \\
\text { the Congo }\end{array}$ & 89,561 & 76,412 & 2,970 & 255 & 72 \\
\hline Yemen & 29,825 & 74,766 & 2,840 & 250 & 67 \\
\hline Mozambique & 31,255 & 71,548 & 2,752 & 239 & 66 \\
\hline Somalia & 15,893 & 70,564 & 2,714 & 242 & 63 \\
\hline Côte d'Ivoire & 26,378 & 68,960 & 2,558 & 243 & 55 \\
\hline Cameroon & 26,545 & 68,088 & 2,540 & 232 & 57 \\
\hline $\begin{array}{l}\text { United Republic of } \\
\text { Tanzania }\end{array}$ & 59,734 & 66,731 & 2,484 & 229 & 55 \\
\hline Afghanistan & 38,928 & 66,159 & 2,469 & 227 & 55 \\
\hline Kenya & 53,771 & 66,064 & 2,407 & 219 & 53 \\
\hline Nigeria & 206,139 & 60,712 & 2,193 & 228 & 43 \\
\hline Burkina Faso & 20,903 & 60,006 & 2,200 & 209 & 47 \\
\hline Mali & 20,249 & 59,879 & 2,230 & 207 & 49 \\
\hline Niger & 24,207 & 59,262 & 2,215 & 215 & 47 \\
\hline
\end{tabular}


Appendix Table 2-Measuring the gap between expected case reporting vs. actual case reporting

\begin{tabular}{|c|c|c|c|c|c|c|c|c|c|c|c|}
\hline Country & Popul. (K) & ACFR & RIPF & EIPF & DR & AARFPM & $\mathbf{C F}$ & DACC & ААНС & AAICUC & AAFC \\
\hline Belgium & 11,589 & $17.4 \%$ & 5.73 & 161 & 0.04 & 310.3 & 8,707 & 49,906 & 50.4 & 3.63 & 2.42 \\
\hline United Kingdom & 67,886 & $17.2 \%$ & 5.82 & 157 & 0.04 & 206.9 & 32,065 & 186,599 & 49.0 & 3.55 & 2.28 \\
\hline Italy & 60,461 & $14.6 \%$ & 6.86 & 178 & 0.04 & 171.3 & 30,739 & 210,717 & 55.6 & 4.02 & 2.97 \\
\hline Sweden & 10,099 & $14.6 \%$ & 6.85 & 161 & 0.04 & 134.4 & 3,256 & 22,317 & 50.2 & 3.64 & 2.40 \\
\hline Hungary & 9,660 & $14.0 \%$ & 7.14 & 163 & 0.04 & 20.1 & 425 & 3,035 & 50.9 & 3.82 & 2.19 \\
\hline Netherlands & 17,136 & $13.4 \%$ & 7.44 & 165 & 0.05 & 137.2 & 5,456 & 40,571 & 51.4 & 3.85 & 2.32 \\
\hline Spain & 46,733 & $12.3 \%$ & 8.13 & 165 & 0.05 & 225.3 & 26,744 & 217,466 & 51.6 & 3.67 & 2.54 \\
\hline Mexico & 128,933 & $15.2 \%$ & 6.57 & 85 & 0.08 & 32.9 & 3,573 & 23,471 & 25.9 & 1.94 & 0.84 \\
\hline Romania & 19,236 & $7.4 \%$ & 13.54 & 162 & 0.08 & 22.6 & 972 & 13,163 & 50.4 & 3.73 & 2.23 \\
\hline Brazil & 212,560 & $11.4 \%$ & 8.78 & 101 & 0.09 & 51.8 & 11,519 & 101,147 & 31.6 & 2.38 & 1.05 \\
\hline US & 329,064 & $7.0 \%$ & 14.35 & 145 & 0.10 & 129.6 & 80,684 & $1,158,041$ & 45.4 & 3.36 & 1.89 \\
\hline Ireland & 4,938 & $6.8 \%$ & 14.66 & 134 & 0.11 & 183.1 & 1,467 & 21,506 & 41.7 & 3.10 & 1.62 \\
\hline Denmark & 5,792 & $5.6 \%$ & 17.87 & 162 & 0.11 & 40.3 & 533 & 9,523 & 50.5 & 3.76 & 2.28 \\
\hline Finland & 5,542 & $5.2 \%$ & 19.39 & 170 & 0.11 & 18.9 & 271 & 5,254 & 53.1 & 3.93 & 2.58 \\
\hline Switzerland & 8,655 & $5.2 \%$ & 19.34 & 164 & 0.12 & 75.2 & 1,542 & 29,822 & 51.2 & 3.72 & 2.37 \\
\hline Algeria & 43,852 & $11.3 \%$ & 8.82 & 72 & 0.12 & 16.2 & 507 & 4,474 & 22.8 & 1.71 & 0.71 \\
\hline Germany & 83,783 & $4.6 \%$ & 21.66 & 174 & 0.12 & 32.0 & 7,533 & 163,175 & 54.3 & 3.93 & 2.80 \\
\hline World & $\underline{7,794,799}$ & $\underline{8.2 \%}$ & 12.13 & $\underline{96}$ & 0.13 & 36.6 & 285,760 & $3,465,608$ & $\underline{\mathbf{3 0 . 0}}$ & $\underline{2.26}$ & $\underline{1.00}$ \\
\hline Portugal & 10,196 & $4.5 \%$ & 22.31 & 176 & 0.13 & 39.9 & 1,144 & 25,524 & 55.0 & 4.01 & 2.81 \\
\hline Czech & 10,708 & $3.6 \%$ & 27.59 & 161 & 0.17 & 12.4 & 282 & 7,781 & 50.2 & 3.79 & 2.11 \\
\hline
\end{tabular}




\begin{tabular}{|c|c|c|c|c|c|c|c|c|c|c|c|}
\hline Country & Popul. (K) & ACFR & RIPF & EIPF & DR & AARFPM & $\mathbf{C F}$ & DACC & ААНС & AAICUC & AAFC \\
\hline Bolivia & 11,674 & $7.7 \%$ & 13.07 & 76 & 0.17 & 11.9 & 122 & 1,594 & 24.5 & 1.75 & 0.88 \\
\hline Ecuador & 17,643 & $7.3 \%$ & 13.77 & 77 & 0.18 & 143.8 & 2,145 & 29,538 & 25.4 & 1.88 & 0.85 \\
\hline Iran & 83,993 & $6.9 \%$ & 14.57 & 78 & 0.19 & 128.0 & 6,685 & 97,424 & 22.3 & 1.78 & 0.62 \\
\hline Philippines & 109,581 & $7.9 \%$ & 12.70 & 62 & 0.20 & 13.2 & 726 & 9,223 & 18.5 & 1.50 & 0.50 \\
\hline Egypt & 102,335 & $8.2 \%$ & 12.13 & 54 & 0.22 & 11.3 & 533 & 6,465 & 17.5 & 1.45 & 0.46 \\
\hline Norway & 5,421 & $2.9 \%$ & 34.86 & 152 & 0.23 & 20.2 & 224 & 7,809 & 47.4 & 3.49 & 2.04 \\
\hline Dominican Republic & 10,847 & $4.9 \%$ & 20.24 & 83 & 0.24 & 41.8 & 393 & 7,954 & 25.7 & 1.89 & 0.87 \\
\hline Peru & 32,972 & $4.3 \%$ & 23.42 & 94 & 0.25 & 62.3 & 1,961 & 45,928 & 28.7 & 2.13 & 0.95 \\
\hline Turkey & 84,339 & $3.0 \%$ & 32.82 & 94 & 0.35 & 47.7 & 3,841 & 126,045 & 29.4 & 2.23 & 0.95 \\
\hline Somalia & 15,893 & $7.2 \%$ & 13.88 & 29 & 0.48 & 15.7 & 52 & 722 & 8.9 & 0.80 & 0.21 \\
\hline Chile & 19,116 & $1.6 \%$ & 60.88 & 122 & 0.50 & 11.9 & 323 & 19,663 & 38.1 & 2.81 & 1.41 \\
\hline Israel & 8,655 & $1.6 \%$ & 62.82 & 113 & 0.55 & 20.6 & 258 & 16,208 & 35.3 & 2.54 & 1.44 \\
\hline Burkina Faso & 20,903 & $7.6 \%$ & 13.24 & 23 & 0.57 & 15.4 & 50 & 662 & 7.2 & 0.69 & 0.15 \\
\hline Cameroon & 26,545 & $6.0 \%$ & 16.62 & 27 & 0.62 & 25.1 & 125 & 2,077 & 8.4 & 0.76 & 0.19 \\
\hline Mali & 20,249 & $6.9 \%$ & 14.44 & 23 & 0.62 & 11.9 & 39 & 563 & 7.3 & 0.68 & 0.16 \\
\hline Niger & 24,207 & $6.1 \%$ & 16.30 & 24 & 0.69 & 12.2 & 46 & 750 & 7.3 & 0.71 & 0.15 \\
\hline Afghanistan & 38,928 & $4.5 \%$ & 22.16 & 26 & 0.85 & 17.3 & 122 & 2,704 & 8.1 & 0.75 & 0.18 \\
\hline Saudi Arabia & 34,815 & $0.9 \%$ & 105.93 & 45 & 2.34 & 24.4 & 255 & 27,011 & 12.4 & 1.04 & 0.30 \\
\hline
\end{tabular}


medRxiv preprint doi: https://doi.org/10.1101/2020.08.31.20185223.this version posted September 2, 2020. The copyright holder for this preprint (which was not certified by peer review) is the author/funder, who has granted medRxiv a license to display the preprint in perpetuity.

\author{
It is made available under a CC-BY-NC-ND 4.0 International license.
}

